\title{
迅速液體渗炭窒化法の研究
}

\author{
足立彰*富 田清* \\ INVESTIGATION OF CARBONITRIDING IN 'THE \\ ACTIVATED LIQUID \\ Akira Adachi Prof. Dr. Eng., and Kiyoshi Tomita
}

\begin{abstract}
Spopsis:
A hard surface could be obtained rapidly and satisfactorily on low carbon steels by means of a cyaniding or liquid carburizing bath. Steel treated by this method absorbed both carbon and nitrogen from the molten salts. The carburizing and nitriding action depended primarily on the sodium cyanide catalized by the presence of alkaline earth salts-usually, barium, calcium and sodium salts. The bath activated in the presence of calcium cyanamide, caused the rate of penetration of carbon and nitrogen ințo steel to increase more effectively. The best results were obtained when the mixture consisted of $20 \% \mathrm{NaCN}, 27 \% \mathrm{BaCl}_{2} 25 \% \mathrm{NaCl}, 28 \% \mathrm{Na}_{2} \mathrm{CO}_{\mathrm{g}}$ and $3 \mathrm{~g}$ per 5 minutes $\mathrm{CaCN}_{2}$ addition, and temperature were $800^{\circ} \mathrm{C}$. The technique of the addition of cyanide must be followed under care, because calcium cyanamide decomposed very rapidly in the batis.
\end{abstract}

\section{I. 緒訇}

機械器具部分品として表面踟䖩を受け易い部分の表面

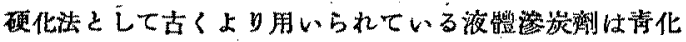

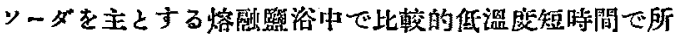
期の目的を果すのであるが，份一層迅渠に此心目的を

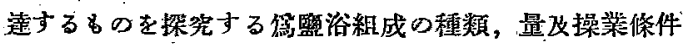
起種々器化させて調查した。特に石灰䍿素, 添加の方法

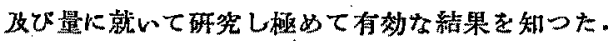

\section{II. 實 驗 方 法}

試科は $10 \mathrm{~mm} \phi \times 18 \mathrm{~mm}$ で第 1 表の成分を持つ低炭 第 1 表 使用荻素除分析結果

\begin{tabular}{c|c|c|c|c|c|c|c}
\hline $\mathrm{C}$ & $\mathrm{Si}$ & $\mathrm{Mn}$ & $\mathrm{P}$ & $\mathrm{S}$ & $\mathrm{Cu}$ & $\mathrm{Or}$ & $\mathrm{Ni}$ \\
\hline 0.07 & 0.01 & 0.53 & 0.011 & 0.024 & 0.17 & 0.08 & 0.01 \\
\hline
\end{tabular}

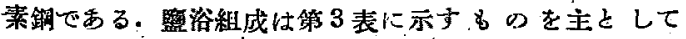
$\mathrm{NaCN}, \mathrm{BaOl}_{2}, \mathrm{BaCO}_{3}, \mathrm{CaCN}_{2}$ の影舫を調查した。 石灰等素D組成は第 2 表に示す。

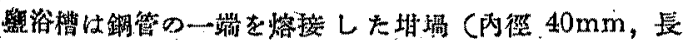

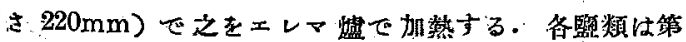

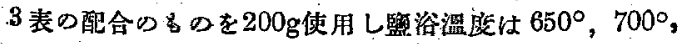
$750^{\circ}, 800^{\circ}, 850^{\circ},{ }^{\circ} 900^{\circ} \mathrm{C}$ の名浿度で2洔間試料を浸
筑 2 表 石灰䇪素の分析成分

\begin{tabular}{c|c|c|c|c}
\hline $\mathrm{CaON}_{2}$ & $\left(\mathrm{~N}_{2}\right)$ & $\mathrm{CaS}$ & $\mathrm{CaO}$ \\
\hline 55.74 & \multicolumn{2}{|c|}{19.50} & 2.37 & 23.69 \\
\hline $\mathrm{MgO}$ & $\mathrm{Al}$ & $\mathrm{Fe}$ & $\mathrm{Si}$ & $\mathrm{C}$ \\
\hline 0.94 & 1.82 & 1.81 & 2.74 & 12.12 \\
\hline
\end{tabular}

请，其の間 30 分每に舆浴を分析し $\mathrm{NaCN}$ 含有量を一

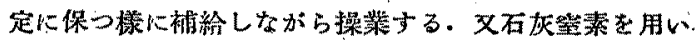

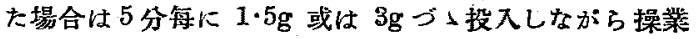
した.そして試料は取出後空冷し， $800^{\circ} \mathrm{C}$ に賞空加熱後

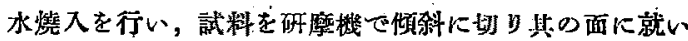
てビッカース硬度試驗(荷重 $5 \mathrm{~kg}$ )を行い，ビッカース 硬度一硬化深度 $\mathrm{mm}$ ○曲線を或く。

\section{III. 實驗結果（A)}

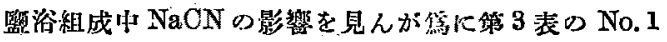
No. 2 , No. 3 に就 $750^{\circ} \mathrm{C}, 800^{\circ} \mathrm{C} に て$ 1 5 時間處 理せるものD硬化筧を調查したが1例として $800^{\circ} \mathrm{O} 2$

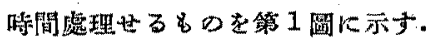

圆に示す如く $\mathrm{NaON} 20 \%$ 心場合が教果最大で，次心

\section{* 大阪大學工學部}


第3表 監 浴 满 D配 合 (\%)

\begin{tabular}{|c|c|c|c|c|c|c|c|}
\hline 番 嘣 & $\mathrm{NaCN}$ & $\mathrm{BaCl}_{2}$ & $\mathrm{KCl}$ & $\mathrm{NaCl}$ & $\mathrm{Na}_{2} \mathrm{CO}_{3}$ & $\mathrm{BaCO}_{\mathrm{s}}$ & $\mathrm{CaCN}_{2}$ \\
\hline $\begin{array}{l}\text { No. } 0 \\
\text { No. } 1 \\
\text { No: } 2 \\
\text { No. } 3 \\
\text { No. } 4\end{array}$ & $\begin{array}{l}\overline{10} \\
20 \\
30 \\
20\end{array}$ & $\begin{array}{r}45 \\
: \quad 50 \\
\quad 27 \\
: \quad 25 \\
\end{array}$ & $\begin{array}{l}30 \\
12 \\
20 \\
25\end{array}$ & $\begin{array}{l}\overline{8} \\
25 \\
-\end{array}$ & $\begin{array}{r}25 \\
20 \\
-28 \\
25 \\
-\end{array}$ & $\frac{\bar{z}}{55}$ & $\begin{array}{l}= \\
=\end{array}$ \\
\hline $\begin{array}{l}\text { No.0' } \\
\text { No.1' } \\
\text { No.2' } \\
\text { No.3' } \\
\text { No.4' }\end{array}$ & $\begin{array}{l}\overline{10} \\
20 \\
30 \\
20\end{array}$ & $\begin{array}{l}45 \\
50 \\
27 \\
25 \\
-\end{array}$ & $\begin{array}{l}30 \\
12 \\
20 \\
25\end{array}$ & $\begin{array}{r}-8 \\
25 \\
- \\
-\end{array}$ & $\begin{array}{l}25 \\
20 \\
28 \\
25 \\
-\end{array}$ & $\therefore \overline{-}$ & $\begin{array}{c}1 \cdot 5 g / 5 \min \\
z \\
\prime \prime\end{array}$ \\
\hline No.2" & 20 & 27 & - & 25 & 28 & - & $3 \mathrm{~g} / 5 \mathrm{~min}$ \\
\hline
\end{tabular}

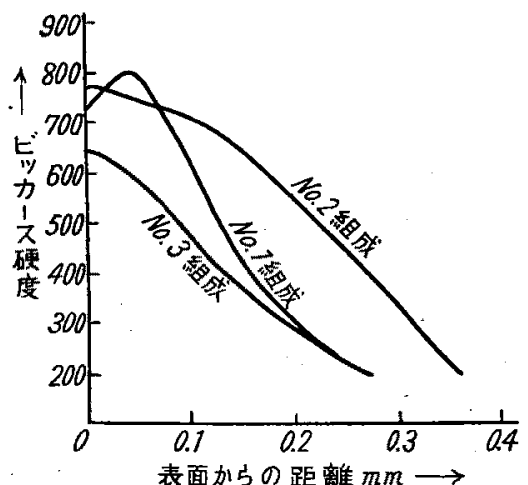

第1 1 圆 No.1,2,3 配合のビッカース硬度一硬化深度

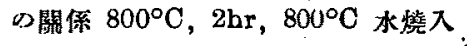

$\mathrm{NaCN} 10 \%$ ，最小なるるのは $\mathrm{NaCN} 30 \%$ で预想を裹切

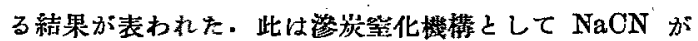

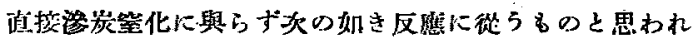
3.

$$
\begin{aligned}
& \left.2 \mathrm{NaCN}+\mathrm{BaCl}_{2} \rightarrow 2 \mathrm{NaCl}+\mathrm{BaCCN}\right)_{2} \\
& \mathrm{Ba}(\mathrm{CN})_{2}+3 \mathrm{Fe} \rightarrow \mathrm{Fe}_{3} \mathrm{C}+\mathrm{BaCN}_{2} \ldots .
\end{aligned}
$$

又新 $\mathrm{Ba}(\mathrm{CN})_{2}+\mathrm{NaCO}_{3} \rightarrow \mathrm{BaO}+2 \mathrm{NaCNO}$

又仕 $2 \mathrm{NaCN}+\mathrm{O}_{2} \rightarrow 2 \mathrm{NaCNO}$

$$
4 \mathrm{NaCNO} \rightarrow \mathrm{Na}_{9} \mathrm{CO}_{3}+2 \mathrm{NaCN}+\mathrm{CO}+2 \mathrm{~N} \cdots \cdots \text { (5) }
$$

以上 5 式上曰 $\mathrm{NaCN}$ 酸化して $\mathrm{NaONO}$ と可此肪

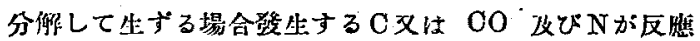
に與るものと溇えられている故, NaCNO 心生成是が丁 度 20\% NaCN の No.2 配合心場合が最大であつた篇此

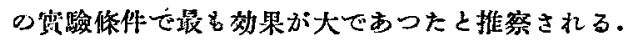

$\mathrm{BaOl}_{3}, \mathrm{NaCO}_{3}$ ○代りに $\mathrm{BaCO}_{3}$ 支配合したる $\mathrm{No.4}$

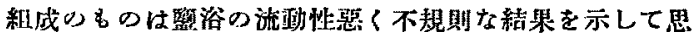

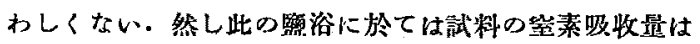
相淌火きい。

\section{IV. 實驗結果 (B)}

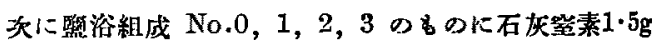
を 5 分間每に加之た No.1'，2'，3' の操業時間 2 時間，

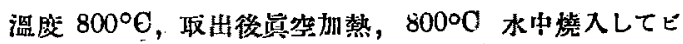
ッカー ス硬度一硬化深度の關保を示す之第2 2 圆の如し.

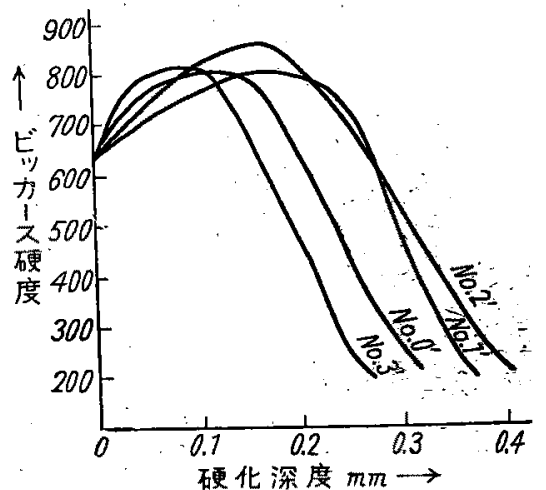

第与嫡 No. $0^{\prime}, 1^{r}, 3^{t}$ 組成に估るビッカーメ硬度一 硬化深度の關係

表面硬废は何れ。 $640 \mathrm{VHN}$ ，最高硬度は No. $0^{\prime}, 1$ r 組成は $820 \mathrm{VHN}$, No.3 ${ }^{r}$ 組成は $810 \mathrm{VHN}$ であるが， No. $2^{\prime}$ 組成は 860 VHN 示し, 又硬化深等。 $0.4 \mathrm{~mm}$

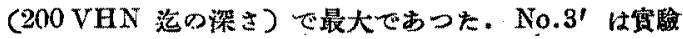
絬果 (A) と同样硬化樑度, 最高硬度共最低の值を示し た。然しながら以上 4 種の配合は石灰堂素を使用しな

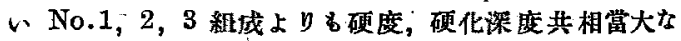

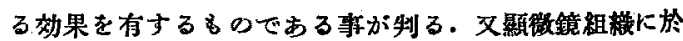

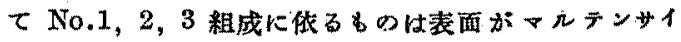

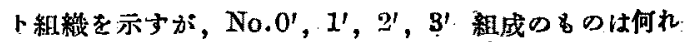

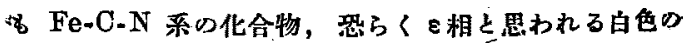

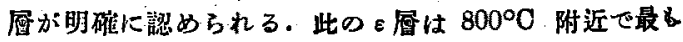


多く出來、其机以上の溫度では急激に淢少し $900^{\circ} \mathrm{C}$ 附

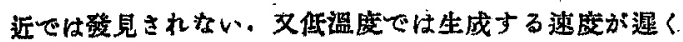

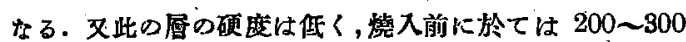

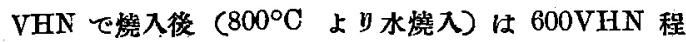

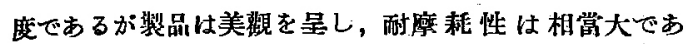
万.

第 3 猲は No.2 組成に依り $700^{\circ}, 750^{\circ}, 800^{\circ}, 850$ ${ }^{\circ} \mathrm{C}$ の各溫度で 2 時間㝿理し $800^{\circ} \mathrm{C}$ 上り水中烍入した るの」硬度一硬化深度の曲線である．此れに依り $800^{\circ} \mathrm{C}$

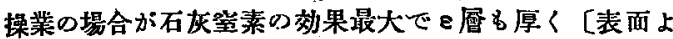
り最高硬度に造する距価倠の大なる程 $\varepsilon$ 層が大である」最 高硬度る大きい.850 $\mathrm{C}$ では硬化深度は大であるが[山 心部汽硬度增大している]最高硬度は急激に诚少する。 これは石灰瑟素が投入後面ちに分解し試料に何ら作用を 興えずして逃げる䈑である。

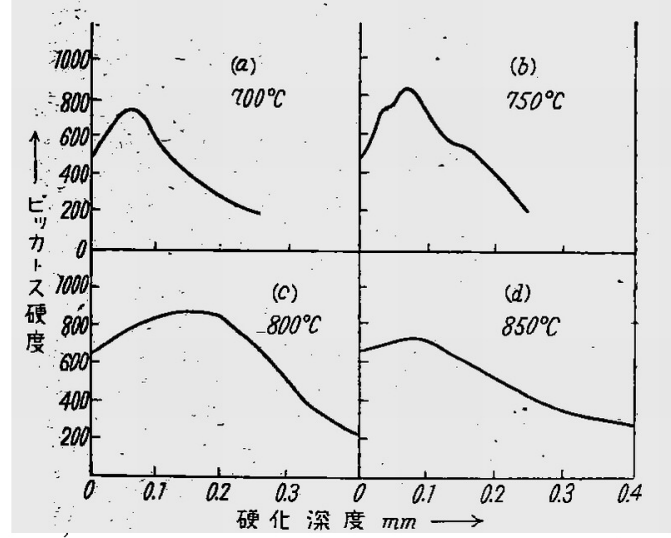

舒 3 圆 $\mathrm{No.2}$ 組成心監浴に於て $700^{\circ}, 750^{\circ}, 800^{\circ}$

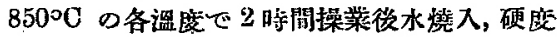
一硬化深度の關係

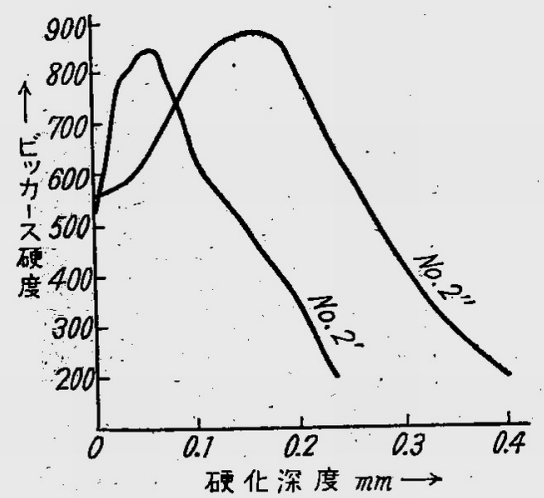

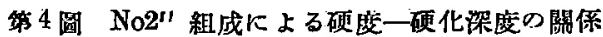
ZƯ No.2' 組成の比輘 操菜溫店 $750^{\circ} \mathrm{C}$
次に石灰䈏素添加星を No.2' 組成の 2 倍即ち $3 \mathrm{~g}$ を 5 分間得心投入する No.2 ${ }^{\prime \prime}$ 組成で 2 時闌，溫度 $750^{\circ} \mathrm{C}$ 取出後水輹入し硬度試臨を行いたるるのを第 4 圖に比較

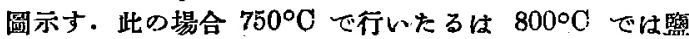

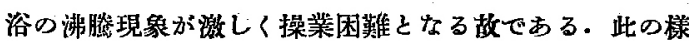

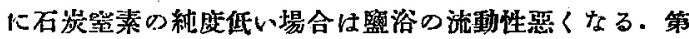
4 圆に示す椂に No2" 組成に依るむの仕硬度 $880 \mathrm{VHN}$ を示し又硬化深度を $N o .2^{\prime}$ 組成の $800^{\circ} \mathrm{C}$ 依る者と ほが同程度心值を示し No.2'組成の. $750^{\circ} \mathrm{C}$ 上りる造 人大きい效果を得, 又白色の $\varepsilon$ 層の厚さる各組成中最大 を示した。

\section{V. 顯徽鏡組織に就いての考察}

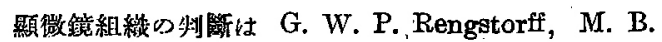

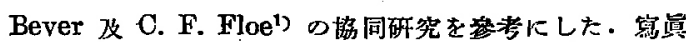
1 は No.2' 配合の整浴て $800^{\circ} \mathrm{O} 2$ 時間處理, $800^{\circ} \mathrm{O}$ 水

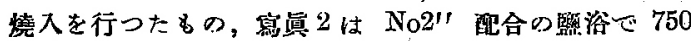

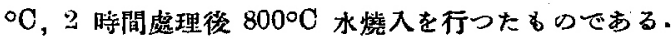

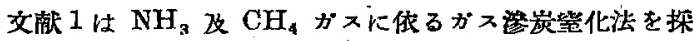
用している。

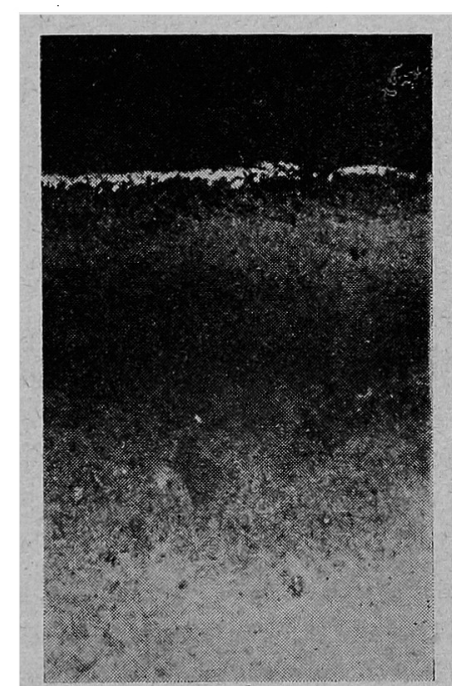

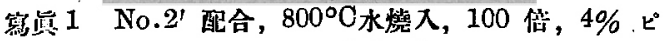
クリン酸アルュール溶液腐搶

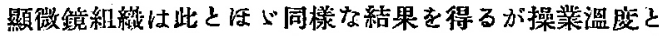

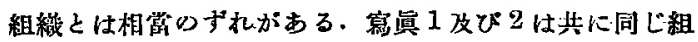
織を示す郎ち最裴面の白色部分は $\mathrm{Fe}-\mathrm{O}-\mathrm{N}$ 系の\&層匹 ありとの層の次に此机を又 $\mathrm{Fe}-\mathrm{N}-\mathrm{C}$. 系のオーステナ1 トとマルテンサイトの混合物があり两部に逌むに從い、 ルテンサイトの混合割合が增犬し遂にマルデンサイトの 


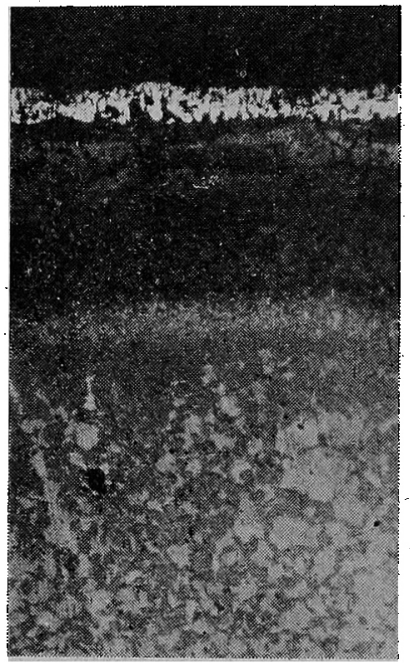

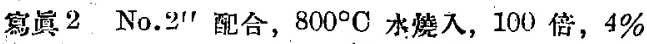
ビクリン酸アルコール溶液磨领

あになる・更に進めばマルテンサイトとフェラ、トい 混合組織，以上フェライトい量加楂大しマルテンサイト はツルースタイト，ソルバイトを變化する．此變化は

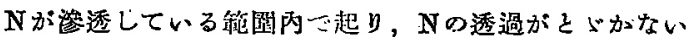
部分はフェライドパーライトを成つている。硕度は白 色 8 濖は比較的低〈 $600 \mathrm{VHN}$ 前後で次のオーステォイ トナマルテンサイははマルテンサイトの嫶加に比例して 坦大し全マルテンサイト屡に於て最高 800 \%900VHN を示す。この屡を過ぎるとフェライトが混合する故に硬 度は急湤に诚少する。な扣 8 層之オーステナイト十マル テンサイト層のけ間に熙色に表われる層がある。此机は

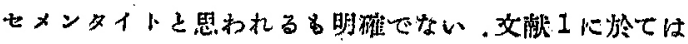
$\mathrm{Fe}_{3} \mathrm{C}$ と掌量の $\mathrm{Fe}_{3} \times(X=\mathrm{O}+\mathrm{N})$ の存在を $\mathrm{X}$ 線分析

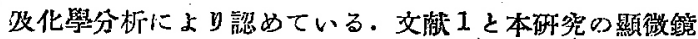
組䖻を比較すれば，文献 1 は何れる $\mathrm{CH}_{4}$ と $\mathrm{NH}_{3}$ の湿

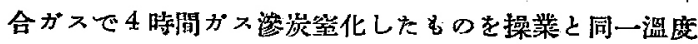
より油熞入を行つている・これに依れば $700^{\circ} \mathrm{C}$ 場合は 最表面がセメンタイト十 トナマルテンサイトの徆に成つていて本研究の $750^{\circ} \mathrm{C}$, $800^{\circ} \mathrm{C}$ の租緎と似ている，然し $760^{\circ} \mathrm{C}$ 及び $815^{\circ} \mathrm{C}$ に 於ては何れる最表面がセメンタイトせ次にオーステナイ ト十マルテンサイトとなりを相い存柱を認めていない。

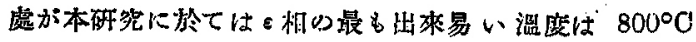

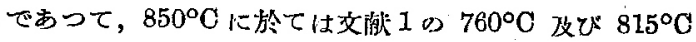

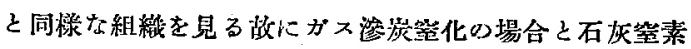

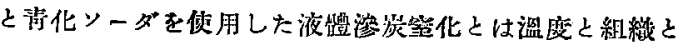

の間に相賞ずれがある事が分る。

\section{·V. 結 論}

(1) $\mathrm{No} .1,2,3$ 唒合, 舅 $\mathrm{NaCN} 10 \%, 20 \%, 30$

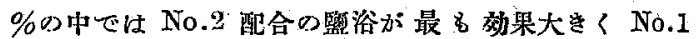
加此机に次き No. 3 は最名效果少い。

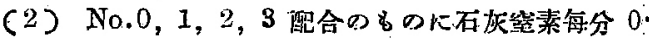
$3 \mathrm{~g}$ の割合で添加しながら操業するNo.0 $0^{\prime}, 1^{\prime}, 2^{\prime}, 3^{\prime}$ 組 成の中では(1) 己同様 $\mathrm{NaCN} 20 \%$ Ð $\mathrm{No.} 2^{r}$ 配合方最

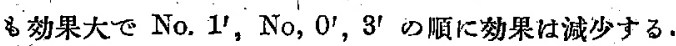

(3) 石皮篦素添加した場合は添加しない場合に比し

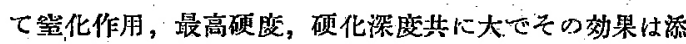
加量に比例して算大するが等分 $0.6 \mathrm{~g}$ 以上の添加昷ては

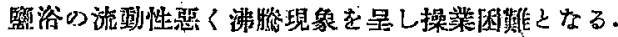

(4) 石灰䆓素を用いたる場合，其の效果最大を示方

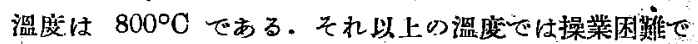
然も效果は全く然くなる。

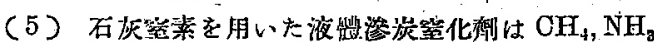

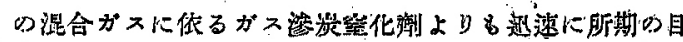

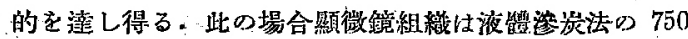

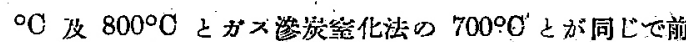
者 $850^{\circ} \mathrm{C}$ 心縕織は後者の $760^{\circ} \mathrm{C} ; 815^{\circ} \mathrm{C}$ と同柡な埗果 を示す。

(6) $\mathrm{BaOl}_{2}$ \& $\mathrm{Na}_{2} \mathrm{OO}_{3}$ 代 $\mathrm{y}$ K $\mathrm{BaCO}_{3}$ を配合し 石灰獒素を用いないで青化ソーダゅみで操亚した場合は 效果が不規則であるが，此机に石炏瑟素を朋いたる場合

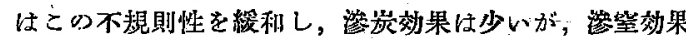
は大となる。

(7)石灰紫素使用大依り $\mathrm{NaCN} に$ 依るシアンガス

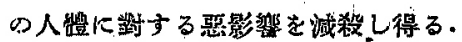

\section{(昭和 28 年 1 月等稿) 文 献}

1) G. W. H. Rengstorff, M: B. Bever and C.F. Floe: Trans. Amer. S.c. Met, 43 (1951) 378/ 403

2) G: W. H Rengstorff, M. B. Bever and C. F. Floe: Trans. Amer. Soc Met., 49 (1951) 342/ $\mathbf{3 7 6}$

3) Robert. J. Peter: Metals Handbook (1948) 692

4) 高橋源助：工大學嚾；昭 12.90

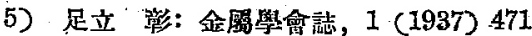

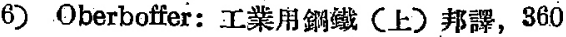

